\title{
Plant Ionomics: A Platform for Identifying Novel Gene Regulating Plant Mineral Nutrition
}

\author{
Kar Satismruti ${ }^{1}$, Natesan Senthil ${ }^{2 *}$, Sampathrajan Vellaikumar ${ }^{2}$, Rajagopalan Veera Ranjani ${ }^{1}$, \\ Muthurajan Raveendran ${ }^{1}$
}

${ }^{1}$ Department of Plant Biotechnology, Center for Plant Molecular Biology and Biotechnology, Tamil Nadu Agricultural University, Coimbatore, India; ${ }^{2}$ Department of Plant Molecular Biology and Bioinformatics, Center for Plant Molecular Biology and Biotechnology, Tamil Nadu Agricultural University, Coimbatore, India.

Email: *senthil_natesan@tnau.ac.in

Received January $5^{\text {th }}, 2013$; revised February $1^{\text {st }}, 2013$; accepted March $1^{\text {st }}, 2013$

Copyright (c) 2013 Kar Satismruti et al. This is an open access article distributed under the Creative Commons Attribution License, which permits unrestricted use, distribution, and reproduction in any medium, provided the original work is properly cited.

\begin{abstract}
In the present era of genomics, ionomics is one of the major pillars for the structural and functional genomic study. The complete set of ions present in an organism is referred to as the ionome of the organism. Hence, the ionomics is defined as the, "study of quantitative complement of low molecular weight molecules present in cells in a particular physiological and developmental state of the plant" [1]. The complete ionomic profiling of the plants are done by using a number of analytical tools like ICP-MS, ICP-OES, X-Ray crystallography, Neutron Activation Analysis (NAA) etc. All these analytical tools gave complete profile of the ions present in the plants. These data are stored in a database called PiiMS (Purdue Ionomics Information Management System) [2]. The huge data available in the database helps in the forward and reverse genetic approach for studying the structural and functional genomics of the particular organism. This review describes the role of the ionomic study in crop plants like arabidopsis, rice and maize.
\end{abstract}

Keywords: DNA Microarray; Functional Genomics; Ions; Ionome; Ionomics; Mineral Nutrition

\section{Introduction}

Plants, being sessile in nature, take nutrients in the water soluble form as ions. Based upon the plant requirement, nutrient ions are classified into three categories: 1) macronutrients, 2) micronutrients, 3) beneficial elements. Among the 92 elements, identified 17 elements are found to be essential for almost all the plants. The elements required in large amount, i.e., $>0.1 \%$ dry mass, are named as the macronutrients which include $\mathrm{C}, \mathrm{H}, \mathrm{O}, \mathrm{N}, \mathrm{S}$, $\mathrm{P}, \mathrm{Ca}, \mathrm{Mg}, \mathrm{K}$ and those which are required in very low amount, i.e., $<0.01 \%$ of dry mass, are referred to as the micronutrients/trace elements. These include $\mathrm{Ni}, \mathrm{Mo}, \mathrm{Cu}$, $\mathrm{Zn}, \mathrm{Mn}, \mathrm{B}, \mathrm{Fe}$ and $\mathrm{Cl}$. Some of the beneficial elements are $\mathrm{Na}, \mathrm{Co}, \mathrm{Al}, \mathrm{Se}, \mathrm{Si}$, which promote growth and may be essential to some of the plants. Moreover, the better growth and development of the plant depends upon the balanced supply of those nutrients to the plants [3]. The plant system itself has an inbuilt mechanism for ion homeostasis in which it regulates the ion accumulation and deficiency. With the advancement in the field of genomic

\footnotetext{
"Corresponding author.
}

study the genomic level regulation of the ions in the plant system has been studied which pave the path for the discovery of the novel gene with its function. Ionomics mainly focuses on the total ionome profile of the organism and how these ions are regulated in the organism's body for a balanced metabolic process. Hence, like transcriptomics, proteomics and metabolomics, ionomics is also a novel approach for the plant functional genomics study. Hence, ionomics is one of the most important pillar of the functional genomics. [4] This article mainly focuses on the total amount of ions present in the plant system and how the level of the ions is maintained in the system.

\section{Plant Mineral Nutrition}

In addition to oxygen, carbon dioxide and water, plants require at least 14 mineral elements for adequate nutrition [5,6]. Deficiency in any one of these mineral elements reduces plant growth and crop yields. Plants generally acquire their mineral elements from the soil solution. Six mineral elements, nitrogen $(\mathrm{N})$, phosphorus $(\mathrm{P})$, 
potassium (K), calcium (Ca), magnesium (Mg) and sulphur (S), are required in large amounts, whilst chlorine $(\mathrm{Cl})$, boron $(\mathrm{B})$, iron $(\mathrm{Fe})$, manganese $(\mathrm{Mn})$, copper $(\mathrm{Cu})$, zinc (Zn), nickel (Ni) and molybdenum (Mo) are required in smaller amounts. In addition, high concentrations of mineral elements in the soil solution can inhibit plant growth and reduce crop yields [5-7]. Generally, plant mineral nutrients are water soluble in nature and hence can be absorbed by the plant roots along with water. These mineral ions traverse through the root via apoplastic (extracellular) and/or symplastic (intracellular) pathways to the stele, where they will be loaded to the xylem for transport to the shoot. All the cytotoxic cations must be transported either through apoplast or through symplast in the chelated form. Some of the minerals are retained in the roots of some plant species. Examples are $\mathrm{Ca}, \mathrm{Mo}, \mathrm{Na}, \mathrm{Cd}$ and $\mathrm{Al}$. The xylem delivers mineral elements to transpiring leaf tissues, where specific cell types take these up from the apoplast. Recirculation of mineral elements within the plant, and the delivery of mineral elements to non-transpiring or xylem-deficient tissues, occurs via the phloem. K, Na, Mg, Cd, N, P, S, Se and Cl are transported readily. But $\mathrm{Fe}, \mathrm{Zn}, \mathrm{Cu}, \mathrm{Mo}$ and iodine (I) are less mobile, and $\mathrm{Mn}$ and $\mathrm{Ca}$ are essentially immobile in the phloem of most plant species [5]. The phloem mobility of B varies between species [8]. The mineral ions which are essential for plant growth and metabolism are known as essential elements. These are required at a very less amount, but any deviation in the optimum concentration of these ions in the plant affects the normal metabolism in the plant. Plants generally take 60 elements from the soil through the root system. Many elements are having beneficial role in the plant body whereas some are toxic to plant. Hence, regulation of these mineral ions exists in the plant. The regulation of this mineral ion concentration in the plant is affected by a number of factors like 1) alteration in the soil mineral concentration, 2) altered plant morphological system, 3) changes in plant nutrient physiology, 4) the changes in the mineral chelating agents. The ions mainly help in the growth and metabolism of the plant. The abundance or the toxicity of the mineral ion in the plant system results in the impaired growth of the plant.

\section{Definition and History of Ionomics}

Plant ionomics is defined as the "study of the quantitative complement of low molecular weight molecules present in cells in a particular physiological and developmental state of the plant [9]. Ionomics is called as the subset of the metabolomics study of the plant body as it is the blended study of the metabolomics and nutrient ions. The ionomic study is the way to study the physiological functional status of the organism [10]. With the advancement of the reliable methods for estimating the total ion con- tent of an organism, the study of the ionomics has been widened the area. Technologies such as gas-liquid chromatography-mass spectrometry (GC-MS) [4] and proton-nuclear magnetic resonance ( $\left.{ }^{1} \mathrm{H}-\mathrm{NMR}\right)$ have proved to be the major breakthrough for the ionomic study of any organism. However, with the advent of the inductively coupled plasma technology and the ability to analyze all the significant element components of a plant simultaneously make the study more accurate. The fusion of the high throughput ion profiling and the advancement of genomics in terms of the complete genome sequencing, DNA microarray and in vitro mutagenesis approach help in the complete study of ionome and ionomics. This suggests that the ionomics has evolved as a functional tool for the analysis of the plants metabolic profile and study the mineral regulation in the body as well as the functioning of other metabolic processes [9].

\section{Analytical Technologies Required for Ionomics}

Analytical techniques give precise and accurate ionomic data. The analytical techniques have two categories like method utilizing the electronic properties (emission, absorption, and fluorescence spectroscopy) or nuclear properties (radioactivity or atomic number) [9]. The different methods of ionome analysis, the methods of the standardization of the chemicals and the sample preparation specific to the particular method of analysis (Figure 1).

\section{Inductively Coupled Plasma}

It is an analytical method used for the detection of the trace mineral elements in the plant and in the environmental materials. The primary goal of ICP is to get elements to emit characteristic wavelength specific light which can then be measured. The technology for the ICP method was first employed in the early 1960's with the intention of improving upon crystal growing techniques.

The ICP is designed to generate plasma by a plasma torch present in it that will create a temperature of 8000 $\mathrm{K}$ making the ions ionized. The flowing gas mainly argon is introduced to the plasma torch and the radio frequency field ionizes the gas, making it electrically conductive. The sample to be analyzed, as an aerosol, is carried into the plasma by a third argon gas stream (carrier gas). Generally, elements to be analyzed by ICP must be in solution. Once ionized the analyte atoms are detected using either optical emission spectrometer or a mass spectrometer. It is of two types like ICP-MS and ICPOES. Working principle of ICP-OES mainly depends upon the wavelength of emission spectrum of the ion [9], whereas, ICP-MS is based upon the measurement of mass and charge ratio of the ion present in the sample. By coupling liquid chromatographic separation of the 


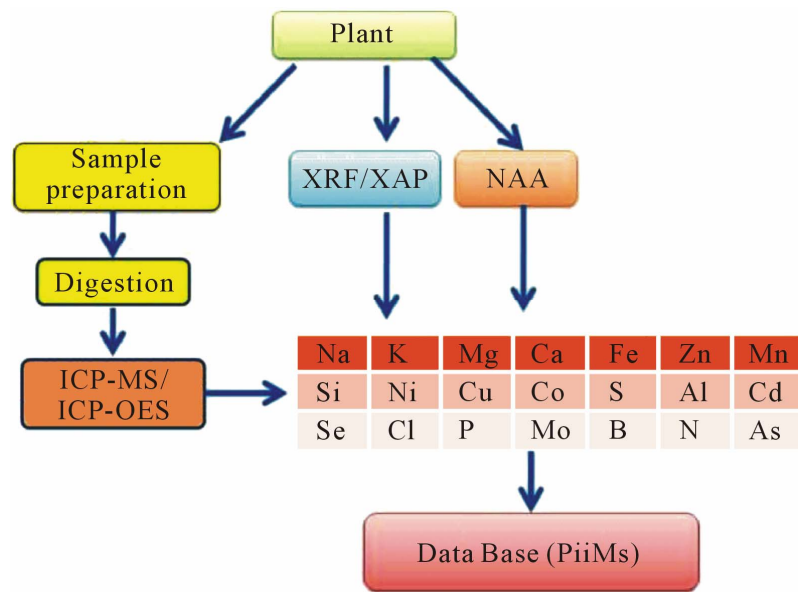

Figure 1. Comparative study of analytical platform in ionomic study; ICP-MS: Inductively coupled plasma mass spectroscopy/optical emission spectroscopy; XRF: X-Ray Fouroscence; XAP: X-Ray Absorption Spectroscopy; NAA: Nutron Acrivation Analysis: PiiMs: Purude Ionomics Information Management System.

chemical species of interest and detection using ICPMS is another method of quantification of the ions. It is the parallel use of ICP-MS and ESI-MS [11].

Although two types of ICP are there, the ICP-MS has some added advantages over ICP-OES. ICP-MS require very less sample and give accurate measurement in less time. Moreover, the noises due to isotopes are less in this method. Still in this method, we can get mis-readings due to the formation of polyatomic elements as a result of the high heat generated. By coupling laser ablation for sample introduction to ICP-MS (LA-ICP-MS), information about the ionome can be acquired without sample preparation and with two-dimensional spatial resolution. However there is limited application of the method in plants [12].

\section{X-Ray Flourescence}

$\mathrm{X}$-Ray fluorescence (XRF) is another method widely use for ionomic study. XRF is generally a nondestructive procedure. Ionomic analysis by XRF can be performed on living plant specimens without compromising their viability. Multi-element screening can also be done using the XRF method [13] in Arabidopsis thaliana seedlings to identify FRD3 mutants with altered ionome. A second novel application of XRF to ionomics is the recent use of synchrotron-based micro XRF as a rapid screening tool for the possible identification of $A$. thaliana seeds with mutant ionomic phenotypes [14]. However, recently XRF micro-tomography and confocal imaging were used to map the three dimensional distribution of the multiple element in various plant samples $[15,16]$. Recently XRF microtomography was used to quantitatively map the three dimensional distribution of various elements intact in A. thaliana seeds for V1T1 transporter. X-Ray Absorption Spectroscopy (XAP) is another method that uses the principle excitation of the specific element of interest.

\section{Neutron Activation Analysis}

Neutron activation method is a special method in capturing the neutrons. The nuclei become radioactive and emit gamma radiation. This radioactivity is the measure of the particular element. It is error free as the neutrons do not have any charge and it is a non destructive process. It is used for the multiple element quantification on the plant samples.

After the quantitative estimation of high throughput ionomic profile by the use of the various analytical techniques the data is used to store in the databases for the further analysis and retrieval (Figure 2).

\section{Bioinformatics in Ionomics}

The advancement of high-throughput phenotyping technologies has created a huge amount of data which can not be maintained without a data management tool. Bioinformatics provides an easily accessible tool for the data storage and retrieval system. Bioinformatics also integrates the workflow information in the genomic-scale data acquisition and validation and provides an open access to data mining and discovery. The Purdue Ionomics Information Management System (PiiMS) (www.purdue. edu/dp/ionomics) [2] provides integrated workflow control, data storage, and analysis to facilitate highthroughput data acquisition, along with integrated tools for data search, retrieval, and visualization for hypothesis development [2]. PiiMS is deployed as a World Wide

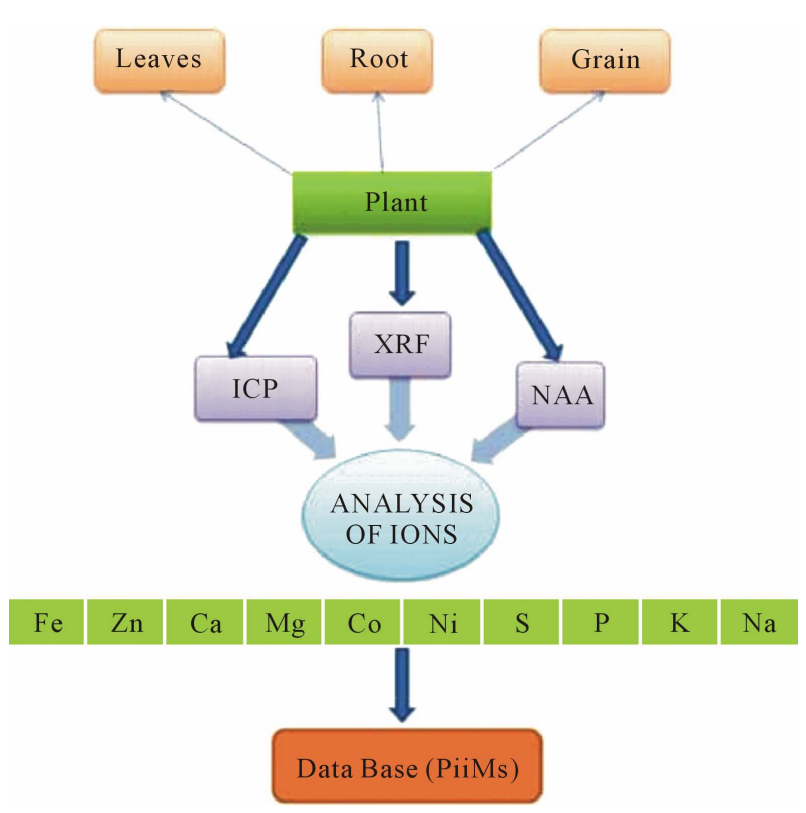

Figure 2. Instrumentational platform of ionomics study. 
Web-enabled system, allowing for integration of distributed workflow processes and open access to raw data for analysis by numerous laboratories. PiiMS currently contains data on shoot concentrations of $\mathrm{P}, \mathrm{Ca}, \mathrm{K}, \mathrm{Mg}, \mathrm{Cu}$, $\mathrm{Fe}, \mathrm{Zn}, \mathrm{Mn}, \mathrm{Co}, \mathrm{Ni}, \mathrm{B}$, Se, Mo, Na, As, and Cd in over 60,000 shoot tissue samples of Arabidopsis (Arabidopsis thaliana), including Ethyl Methane Sulfonate, fast-neutron and defined T-DNA mutants, and natural accession and populations of recombinant inbred lines from over 800 separate experiments, representing over 1,000,000 fully quantitative elemental concentrations.

\section{Ionomics in Identifying Novel Genes}

Ionomics study is one of the methods to identify novel genes regulating the ionome profile in the plant system. Hence, the ionomics is called as the fourth pillar of the functional genomics. The plant mineral nutrition in one of the major physiological process where plant absorbs mineral ions from the soil in the rhizospheric zone via the well developed root system. Starting from the absorption of the mineral ions to the transport to various plant parts and their utilization in the system is driven by many ion regulator proteins. These regulator proteins are encoded by some genes. The advancements in the different analytical techniques and the high throughput data generated by the system made the study of the functional genomics easy. Functional genomics is the study of the "global expression of the gene combined with the DNA sequence data that make the inferences on the gene and protein function" [17-19]. The availability of high throughput phenotypic data helps in the functional genomics approach. These phenotypic data can be used to screen the mapping population with available modern genetic tool in order to identify a novel gene and genomic network regulating the ionome level in the plant system.

A variant population is essential for this type of study. The variation should be at the genetic level. This may be available in nature in the form of natural variant population [20] or can be induced artificially by the mutagenesis approach. Artificial mutagenesis can be done by mutagens which may be a physical mutagen or a chemical mutagen such as EMS [21]. In some cases, the in vitro mutagenesis is found to be the best method, which can be done either by T-DNA tagging [1] or by Transposon tagging method (Figure 3). The genotyping is done on the variant population using modern genetic tools like DNA microarray, Affymetrix [22]. DNA microarray based genotyping is used for the identification of the causal deletion underlying the phenotype of interest $[13,23]$. Except the DNA microarray method, other methods of massively parallel sequencing using the advanced sequencers like 454's GSFlex, Illumina's Solexa and ABI's SOLID are also used, as they have the capacity of rapid sequencing the large region of DNA to identify polymorphism between the mutant and wild type plants. This

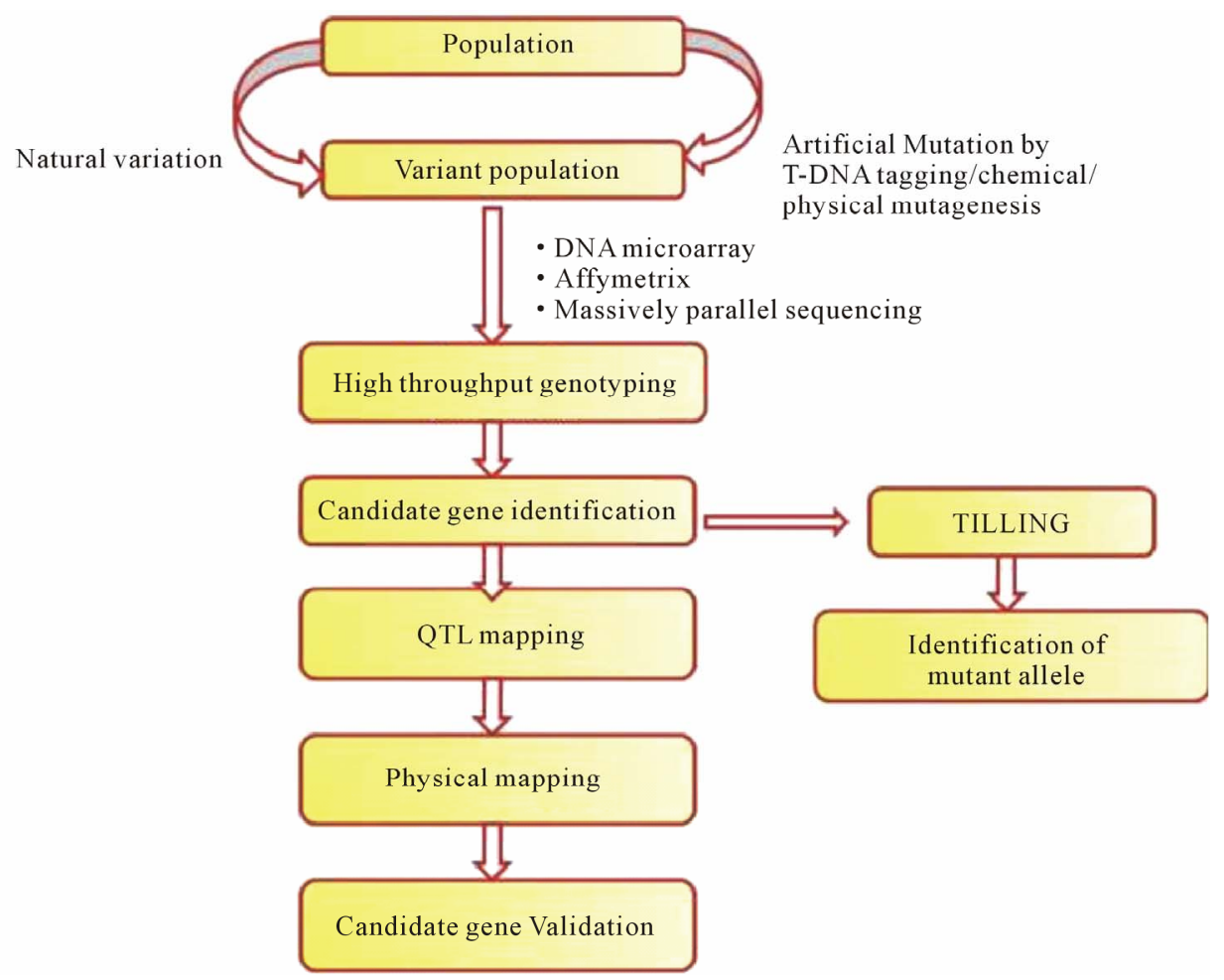

Figure 3. Flow chart showing role of ionomics in fuctional genomics study with the help of ionomics data. 
high throughput genotyping helps in the identification of the causal loci.

After the identification of the candidate gene, the screening for the phenotype is performed for the identification of the mutant allele by TILLING method. The naturally available variant population can also be exploited for the mapping of the QTL concerning the trait of interest. Subsequently, the physical map is being produce by the map based cloning and chromosome walking method which in turn help in validation of the candidate gene.

Till date the ionomics has helped in the study of functional genomics in various ways such as the study of the ion homeostasis in the plant system. In rice, the complete ion profiling helped in the study of the transporters and how they help in the ion transportation. The ion transporters are the proteins which are encoded by the particular set of the family of genes responsible for it. So the ionomic profile study helps the study of interaction of the metal ion with the function of a particular gene for its function and so also the interaction of the ion with the protein for the transportation in the plant system. For example, the $\mathrm{Cu}$ ion is specific to the protein transporters such as RAN1 and HMA5. By mutational inactivation method in Arabidopsis thaliana the function of the gene FRD3 regulating Fe level in the plant has been identified [11]. Using reverse genetic approach, the function of gene AtHKT1 regulating the accumulation of the $\mathrm{Na}$ ion in the shoot and root have been identified. The gene expression profiling has been done by the DNA microarray method using the BSA in Arabidopsis thaliana [24]. By Transposon tagging and nullifying the action of the gene regulating the Mo accumulation has been identified in $A$. thaliana and the function is analyzed by the GUS expression and found that the gene is expressed in almost all parts of the plant [25]. Same study has been done for the identification of the gene accumulating $\mathrm{Cd}$ in the rice plant. They report a gene (OsHMA3) responsible for low Cd accumulation in rice. The results indicated that OsHMA3 from the low Cd-accumulating cultivar limits translocation of $\mathrm{Cd}$ from the roots to the above-ground tissues by selectively sequestrating $\mathrm{Cd}$ into the root vacuoles [26].

Using RNAi method of gene silencing, the function of the MTP3 has been identified which regulates the Fe and Zn homeostasis in the plant system. The ectopic expression of the gene and the vacuolar localization has been identified using the GFP as a selectable marker [9]. For the increased micronutrients like $\mathrm{Fe}$ and $\mathrm{Zn}$ in the maize plant the in vitro mutagenesis has been done and found two genes present on the chromosome 1s [27]. In case of maize using the map based cloning approach, the $M I K$ gene has been identified which is denoted as the lpa3 mutant. This gene helps in lowering the phytate level in the plant and there by increasing the level of divalent cations like Fe and $\mathrm{Zn}$. The study of genetic variation in the microelement and their stability in different environmental condition suggests constitutive expression of the gene [28]. The ferroportin metal efflux proteins FPN1 and FPN2 has been identified to be regulated by Iron Regulated 1 and Iron Regulated 2 gene that function in iron and cobalt homeostasis in arabidopsis [29]. Gene expression profiling in Arabidopsis thalina for $\mathrm{Cu}$ transporters was done using the real-time RT-PCR. This study reveals the function of some novel transporter and the chaperons in the regulation of the $\mathrm{Cu}$ ion homeostasis in the plant. The results indicated a common transcriptional regulation pattern of transporters and chaperone components, in particular transcriptional changes of COPT2, ZIP2, and CCH showed an inverse relation with $\mathrm{Cu}$ content suggesting that these proteins are required to avoid excess and deficit of $\mathrm{Cu}$ [30]. In recent year some other Fe regulator protein has been identified like IRT1 which comes under ZIP family protein [31].

Identifying the gene and mapping the location of the gene helps in studying the gene interaction and pyramiding the genes in the segregating population for the introgression of the trait into the off springs. In dicot plant like Arabidopsis thaliana, the complete ionomic profile study has been done with the help of the ICP-MS method [32]. This study helps in the complete genomic study of the plant with all the QTLs regulating the function of the gene associated with the ionome study. Selecting the widely variant populations collected from different environmental conditions and growing them in controlled environment, the QTL mapping for the ions was done. This study results in the identification of nearly 280 QTLs for nearly 19 elements [32]. In rice genetic mapping has been done for the identification of the QTLs associated with 17 essential elements both in the leaves and in grains. In leaves, there are 36 QTLs and in grains, there are 41 QTLs associated with the elements. These QTLs also show epistatic effect among themselves. Only Se was found to have correlation between leaf and grain [26].

In wheat QTL analysis has been done for the identification and location of the gene regulating the Fe and $\mathrm{Zn}$ in the plant. Two QTLs governing Fe regulation in the plant are present, one in chromosome 2 and other in chromosome 7. However, for the regulation of $\mathrm{Zn}$, there is only one QTL present on chromosome 2 [33]. Similar study has been done in Brassica napus for the QTL study for the ions like B, Ca, Fe, Cu, Mg, P and $\mathrm{Zn}$ using $\mathrm{DH}$ population. A total of 35 QTLs have been identified [34]. Ionomic studies have been done specifically for different ions. In Brassica napus the QTL study has done for B ion [14]. QTL associated with the low phytic acid in maize plant has been mapped to be located on chromo- 
some 1.

\section{Future Prospects}

The ionomics, which is one of the pillar for the functional genomics study, helps us to widen the area of the functional genomics study. It will help in the identification of the gene and the gene network and coordination among the different genes controlling different ion accumulation in the plant system. It will also help in the better understanding the relationship between the ions and identification of the gene and environment interaction at different stages of growth. The identification of the gene regulating the accumulation of the particular ion and its location in the plant help in the marker assisted breeding of the plant with introgression of the gene into the other plant. In this way, the ionomics helps in the nutrigenomics approach for the production of the micronutrient rich food. Many of the ions are toxic for the plant as well as the human beings and the herbivores. Hence, by the knowledge of the genes that regulate the accumulation of the ions, we can manipulate the ionomic profile of the plant system.

\section{Summary}

The advancements in high throughput phenotypic scale profiling of the ions in the plant system help in the identification of the function of the genes. This method serves as a functional genomic tool to discover novel genes in the plant system.

\section{Acknowledgements}

The financial support by Department of Biotechnology, Government of India under the programme support for research and development in Agricultural Biotechnology is greatly acknowledged.

\section{REFERENCES}

[1] D. Salt, I. Baxter and B. Lahner, "Ionomics and the Study of the Plant Ionome," Annual Review of Plant Biology, Vol. 59, 2008, pp. 709-733.

doi:10.1146/annurev.arplant.59.032607.092942

[2] I. Baxter, M. Ouzzani, S. Orcun, B. Kennedy, S. S. Jandhyala and D. E. Salt, "Purdue Ionomics Information Management System (PiiMS): An Integrated Functional Genomics Platform,” Plant Physiology, Vol. 143, 2007, pp. 600-611. doi:10.1104/pp.106.092528

[3] W. Lorraine and D. E. Salt, "The Plant Ionome Coming into Focus," Current Opinion in Plant Biology, Vol. 12, No. 3, 2009, pp. 247-249.

[4] D. E. Salt, "Update on Ionomics," Plant Physiology, Vol. 136, No. 1, 2004, pp. 2451-2456. doi:10.1104/pp.104.047753

[5] H. Marschner, "Mineral Nutrition of Higher Plants,” 2nd
Edition, Academic, London, 1995, pp. 369-379.

[6] K. Mengel, E. A. Kirkby, H. Kosegarten and A. Thomas, "Principles of Plant Nutrition," Springer Science + Business media, Dordrecht, 2001.

[7] R. D. Macnicol and P. H. T. Beckett, "Critical Tissue Concentrations of Potentially Toxic Element,” Plant Soil, Vol. 85, No. 1, 1985, pp. 85-107.

[8] P. H. Brown, N. Bellaloui, M. A. Wimmer, E. S. Bassil, J. Ruiz, H. Hu, H. Pfeffer, F. Dannel and V. Romheld, "Boron in Plant Biology,” Plant Biology, Vol. 4, No. 2, 2002, pp. 205-223. doi:10.1055/s-2002-25740

[9] S. Arrivault, T. Senger and U. Kramer, “The Arabidopsis Metal Tolerance Protein AtMTP3 Maintains Metal Homeostasis by Mediating $\mathrm{Zn}$ Exclusion from the Shoot Under Fe Deficiency and Zn Oversupply,” The Plant Journal, Vol. 46, No. 5, 2006, pp. 861-879. doi:10.1111/j.1365-313X.2006.02746.X

[10] A. B. Robinson and L. Pauling, "Techniques of Orthomolecular Diagnosis,” Clinical Chemistry, Vol. 20, No. 8, 1974, pp. 961-965.

[11] E. E. Rogers and M. L. Guerinot, "FRD3, A Member of the Multidrug and Toxin Efflux Family, Controls Iron Deficiency Responses in Arabidopsis,” Plant Cell, Vol. 14, No. 8, 2002, pp. 1787-1799. doi:10.1105/tpc.001495

[12] T. Punshon, B. P. Jackson, P. M. Bertsch and J. Burger, "Mass Loading of Nickel and Uranium on Plant Surfaces: Application of Laser Ablation-ICP-MS," Journal of Environmental Monitoring, Vol. 6, No. 2, 2004, pp. 153159. doi:10.1039/b310878c

[13] E. Delhaize, P. J. Randall, P. A. Wallace and A. Pinkerton, "Screening Arabidopsis for Mutants in Mineral Nutrition,” Plant Soil, Vol. 155-156, No. 1, 1993, pp. 131-134. doi:10.1007/BF00025001

[14] H. Zhao, S. Lei, X. L. Duan, F. S. Xu, Y. H. Wang and J. L. Meng, "Mapping and Validation of Chromosome Regions Conferring a New Boron-Efficient Locus in Brassica napus," Molecular Breeding, Vol. 22, No. 3, 2008, pp. 495-506. doi:10.1007/s11032-008-9193-3

[15] M. P. Isaure, A. Fraysse, G. Devies, P. Le Lay and B. Fayard, "Micro-Chemical Imaging of Cesium Distribution in Arabidopsis thaliana Plant and Its Interaction with Potassium and Essential Trace Elements,” Biochimie, Vol. 88, No. 11, 2006, pp. 1583-1590. doi:10.1016/j.biochi.2006.08.006

[16] K. Nakano and K. Tsuji, "Development of Confocal 3D Micro XRF Spectrometer and Its Application to Rice Grain,” Bunseki Kagaku, Vol. 55, No. 6, 2006, pp. 427 432. doi:10.2116/bunsekikagaku.55.427

[17] D. Baldwin, V. Crane and D. Rice, “A Comparison of Gel-Based, Nylon Filter and Microarray Techniques to Detect Differential RNA Expression in Plants," Current Opinion in Plant Biology, Vol. 2, No. 2, 1999, pp. 96103. doi:10.1016/S1369-5266(99)80020-X

[18] B. Lemieux, A. Aharoni and M. Schena, "Overview of DNA Chip Technology,” Molecular Breeding, Vol. 4, No. 4, 1998, pp. 277-289. doi:10.1023/A:1009654300686

[19] J. A. Eisen, "Phylogenomics: Improving Functional Predictions for Uncharacterized Genes by Evolutionary 
Analysis,” Genome Research, Vol. 8, 1998, pp. 163-167.

[20] V. G. Sobhana, N. Senthil, M. Raveendran, K. Kalpana, P. Nagarajan, V. Velu, A. Arumugachamy, A. John Joel, S. Vellaikumar, D. Abirami and K. Satismruti, "Exploitation of the Natural Variability for Phytate Phosphorus among the Maize Inbred Lines," 15th ADNAT Convention on Genomics and Biodiversity, Centre for Cellular and Molecular Biology, Hyderabad, 23-25 February 2011, p. 70.

[21] V. G. Sobhana, "Molecular Characterization of Low Phytate Maize (Zea mays L.) Developed through Induced Mutation and Exploitation of Natural Variability for Grain Micronutrient,” PhD Thesis, Tamil Nadu Agricultural University, Coimbatore, 2010.

[22] J. Misson, K. G. Raghothama, J. Ajay, J. Juliette, A. Maryse, B. Richard, O. Philippe, S. Audrey Shauna, R. Norbert, P. Doumas, N. Philippe, H. E. Luis, N. Laurent and M. C. Thibaud, "A Genome-Wide Transcriptional Analysis Using Arabidopsis thaliana Affymetrix Gene Chips Determined Plant Responses to Phosphate Deprivation," Proceedings of the National Academy of Sciences, Vol. 102, 2005, pp. 11934-11939.

[23] S. P. Hazen, J. O. Borevitz, F. G. Harmon, J. L. PrunedaPaz and T. F. Schultz, "Rapid Array Mapping of Circadian Clock and Developmental Mutations in Arabidopsis,” Plant Physiology, Vol. 138, No. 2, 2005, pp. 990997. doi:10.1104/pp.105.061408

[24] A. Rus, I. Baxter, B. Muthukumar, J. Gustin, B. Lahner, et al., "Natural Variants of AtHKT1 Enhance Na+ Accumulation in Two Wild Populations of Arabidopsis," PLoS Genetics, Vol. 2, No. 12, 2006, Article ID: e210. doi:10.1371/journal.pgen.0020210

[25] H. Tomastu, J. Takano, H. Takahasi, W. T. Akiko, N. Shibagaki and T. Fujiwara, "An Arabidopsis thaliana High-Affinity Molybdate Transporter Required for Efficient Uptake of Molybdate from Soil," Proceedings of the National Academy of Sciences, Vol. 104, 2007, pp. 18807-18812. doi:10.1073/pnas.0706373104

[26] G. J. Norton, C. M. Deacon, Z. X. Li, S. Y. Huang, A. A. Meharg and A. H. Price, "Genetic Mapping of the Rice Ionome in Leaves and Grain: Identification of QTLs for 17 Elements Including Arsenic, Cadmium, Iron and Selenium,” Plant Soil, Vol. 329, No. 1-2, 2010, pp. 139-153. doi:10.1007/s11104-009-0141-8

\author{
Abbrevations \\ ICP-MS: Inductively coupled plasma mass spectroscopy. \\ ICP-OES: Optical emission spectroscopy \\ XRF: X-Ray Fouroscence \\ XAP: X-Ray Absorption Spectroscopy
}

[27] V. Raboy, "Origin and Seed Phenotype of Maize Low Phytic Acid 1-1 and Low Phytic Acid 2-1," Plant Physiology, Vol. 124, No. 1, 2000, pp. 355-368. doi:10.1104/pp.124.1.355

[28] V. G. Sobhana, N. Senthil, M. Raveendran, K. Satismruti, P. Nagarajan, Sangeetha, et al., "Genetic Variation and Stability Analysis of Grain Iron and Zinc Concentrations in Maize (Zea mays L.) under Three Environments," Plant, Soil and Environment, 2010 (Submitted Article).

[29] M. Joe, I. R. Baxter, J. Lee, L. Li, B. Lahner, G. Natasha Kaplan, D. E. Salt and L. U. Guerinot, “The Ferroportin Metal Efflux Proteins Function in Iron and Cobalt Homeostasis in Arabidopsis,” The Plant Cell, Vol. 21, 2009, pp. 3326-3338. doi:10.1105/tpc.109.069401

[30] T. Pozo, V. Cambiazo and M. González, “Gene Expression Profiling Analysis of Copper Homeostasis in Arabidopsis thaliana,"Biochemical and Biophysical Research Communications, Vol. 393, No. 2, 2010, pp. 248-252. doi:10.1016/j.bbrc.2010.01.111

[31] T. Yang, W. D. Lin and W. Schmidt, "Transcriptional Profiling of the Arabidopsis Iron Deficiency Response Reveals Conserved Transition Metal Homeostasis Networks," Plant Physiology, Vol. 152, 2010, pp. 21302141. doi:10.1104/pp.109.152728

[32] B. Elizabeth, A. Tilman, I. Anthony, O. Cherie, R. Ana, B. Lahner, H. Owen, Y. Elena, J. F. Harper, L. Mary, M. Zhang, D. Salt and R. Baxter, "Natural Genetic Variation in Selected Populations of Arabidopsis thaliana Is Associated with Ionomic Differences," PLoS ONE, Vol. 5, No. 6, 2010, pp. 11081-11088. doi:10.1371/journal.pone.0011081

[33] V. K Tiwari, R. Nidhi, C. Paeveen, K. Neelam, A. Renuka, G. S. Randhawa, H. S. Dhaliwal, B. Keller and K. Singh, "Mapping of Quantitative Trait Loci for Grain Iron and Zinc Concentration in Diploid a Genome Wheat," Journal of Heredity, Vol. 100, No. 6, 2009, pp. 771-776. doi:10.1093/jhered/esp030

[34] J. Liu, J. Yang, R. Li, S. Lei, C. Zhang, L. Yan, F. Xu and J. Meng, "Analysis of Genetic Factors that Control Shoot Mineral Concentrations in Rapeseed (Brassica napus) in Different Boron Environments,” Plant Soil, Vol. 320, No. 1-2, 2009, pp. 255-266. doi:10.1007/s11104-009-9891-6

NAA: Nutron Activation Analysis PiiMs: Purude Ionomics Information Management System

LA-ICP-MS: Laser Ablation Inductively coupled plasma mass spectroscopy 